\title{
Contextual Modelling of Collaboration System
}

\author{
Purchasing process application
}

\author{
Wafaa DACHRY ${ }^{\# 1}$, Brahim AGHEZZAF ${ }^{\# 1}$, Bahloul BENSASSI ${ }^{\# 2}$, Adil SAYOUTI ${ }^{\# 3}$ \\ ${ }^{\# 1}$ Department of Mathematics and Computer Faculty of sciences, Hassan II University \\ ${ }^{\# 2}$ Department of physics, Faculty of sciences, Hassan II University \\ \#3 Systems Architecture Team, ENSEM, Hassan II University \\ BP 5366, Maarif, Casablanca 20100, Morocco
}

\begin{abstract}
Faced with new environmental constraints, firms decide to collaborate in collective entities and adopt new patterns of behavior. So, this firms' collaboration becomes an unavoidable approach. Indeed, our aim interest in our study is to propose a collaborative information system for supply chain. Our proposed platform ensures cooperation and information sharing between partners in real time. In fact, several questions have to be asked: What is the information nature may be shared between partners? What processes are implemented between actors? What functional services are supported by the platform? In order to answer these questions, we present, in this article, our methodological approach of modelling, called CMCS (Contextual Modelling of Collaborative System).
\end{abstract}

Keywords-collaborative information system; business process; collaborative process; BPMN; CMCS.

\section{INTRODUCTION}

The integration of a collaborative information system within the supply chain has become a key element for improving manufacturing performance [1]. The collaborative information system aims to ensure coordination between different actors in the supply chain. It consists of a set of services developed to better meet user requirements.

To this end, we propose a modelling approach which consists to ensure the evolution of information through the realization of a set of models (business and applicative). These models offer a global vision of the company, partners and collaborative systems. A main feature of our approach is flexibility. This property can be defined as the system ability that can help system to easily adapt to the requested evolutions. The flexibility notion is provided through the separation of the business view from the applicative and technical one. So, we model the business processes and we identify necessary services regardless of application characteristics and technics.

The methodology is based on process approach [2] and adapted to the urbanism model of information system [3].

The business view: it lists the business events that the company must treat, business processes that respond to these events, documents used in these processes and actors who execute them.

The functional view: it describes the functions of information system, such as they are described in the specifications for the implementation of a new application.
Functions can be: the management of a customer's contract, the management of delivery, etc.

The application view: It lists all the applications used by actors to perform functions and equip processes.

The Physical view: It lists all the infrastructure components (hardware, network infrastructure, equipment security, archiving, etc.) that support the system.

So, we present an adaptive model to the urbanism model of information system [4] [5], by adding two other necessary views for the implementation of our collaborative system (strategy and service). Also, the business view contains two contexts (business and collaborative ones).

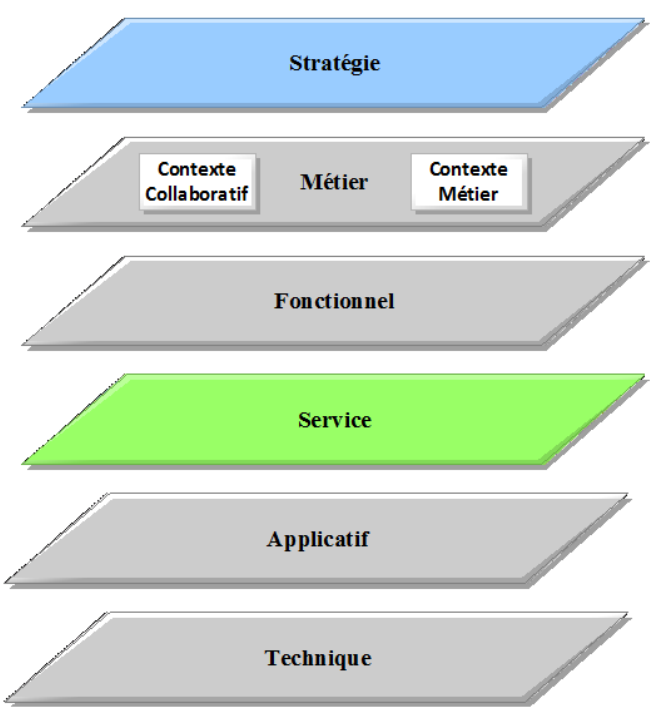

Figure 1. Adaptive model of urbanism model

The principle of CMCS can be summarized as follows: After defining the key processes used in the implementation of our system, they are detailed in activities to bring out the interactions between actors, modelling collaborative processes and determine various business services needed to carry out these processes.

The function blocks are then added in order to coherently organize all business objects. Functional services, which perform the function blocks defined in advance, are exposed by IT services (CRUD service and technical service [6]). 
This paper describes different phases of CMCS approach (Contextual Modelling of Collaborative System) and a practical example for modelling the purchasing process

\section{Contextual Modelling Of Collaboration SYSTEM}

CMCS is a methodological approach in two phases (Study needs, Modelling and Design of the system), each phase contains one or more steps. We present in detail the different phases.

\section{A. Phases of the methodology}

\section{Phase 1: The study needs}

The study needs, first phase of our project, is one of the most difficult phases of our approach. The following phase of CMCS is based on the deliverables of the "study needs".

This phase includes two major steps: developing the business motivation model and the organization of the company.

\section{Deliverable 1: BMM (Business Motivation Model);}

Deliverable 2: Process mapping;

Step 1: Development of business models of motivation

As a preliminary to the establishment of a collaborative architecture, it is important to define objectives and motivations that lead to achieving them. This step should give birth to a business plan indicating the means to implement [7]. To determine these business motivations, we relied on the standard (Business Motivation Model - BMM) proposed by the OMG. It provides an organized structure for the specification and definition of business plans. The construction of business models and application models must be deducted from objectives and strategies, which justifies the use of this standard by our approach CMCS. In the context of CMCS, we focus on the two entities (means and ends) in the development of BMM.

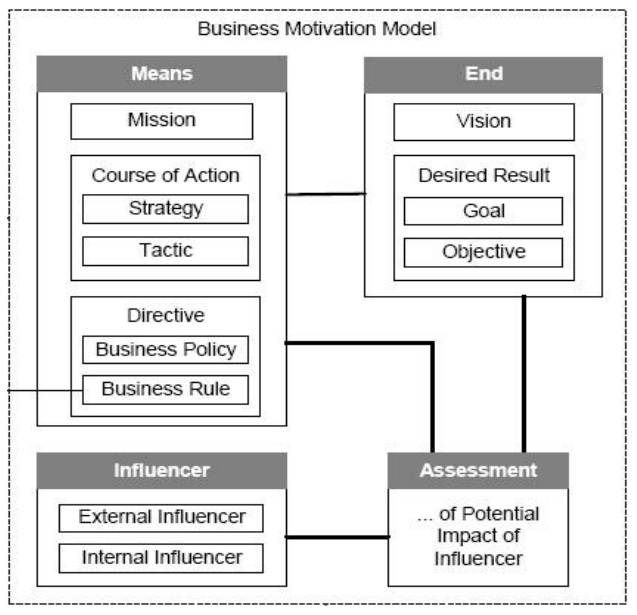

Figure 2. Business Model of Motivation [8]

Step 2: Study of business organization

This step of the approach follows the urbanization principle. One of the main phases of urbanization is the study of enterprise architecture. This involves identifying a set of mapping organizational of the company and its partners. The mapping is used to represent the environment already studied and how it works. This tool is essential at this step; however it must meet a few criteria:

- Global: The mapping should cover all business processes in order to have an overview of operations.

- Systemic: The mapping must be based on a systems approach [9]; the company should be considered as a set of micro-enterprises (subsystems) that operate with each other.

- Understandable: The mapping must be clear and understood by the entire company to allow many uses (business analysis, functional analysis, application analysis, etc.).

\section{Phase 2: Modelling and Design of the system}

The second phase of the process CMCS is the modelling and the design of system. This phase corresponds to the two views (business view and functional view) of the urbanization principle. The objective is to define the various functional necessary services to achieve information system. Various steps constitute this second phase:

Step 1: Business process modelling

Deliverable 1: Model the business process

Step 2: Modelling the collaborative business process

Deliverable 2: Model of the collaborative process

Step 3: Analysis and design of the system

Deliverable 3: UML diagrams (use case, sequence, class)

Step 4: Identification of functional services

Deliverable 4: Models of functional blocks and list of services

Step 1: Business process modelling

This step is based on the mapping of business processes. This step is used to describe business processes and all the activities constituting these processes.

The business processes must meet to one of objectives defined in the business motivation model of the company.

Step 2: Modelling the collaborative business process

To model collaborative processes, we rely on models of business processes of this phase first step. This model follows the BPMN formalism [10] [11], this concept is developed by the OMG; it's a communication tool that facilitates the rapid transition of the design of business processes to their implementation.

The objective of this step is the identification of business activities supported by the collaborative information system.

Step 3: Analysis and design of the system

This step consists to create an abstract representation of our system. It requires the use of an adequate method for the creation of different models on which we rely for the implementation of the system. The step aims to study 
expectations of users and to identify elements involved in the collaborative system, their structures and their relationships.

In addition, the design consists to provide technical solutions to definite descriptions in the analysis. Objectoriented design focuses on defining software objects and how they work together. We use in this step the language UML (Unified Modelling Language) [12] in order to present three diagrams (use case, sequence, class).

Step 4: Identification of functional services

Based on the previous two steps, the description of collaborative business processes and analysis and design system, we generate the functional blocks [13] that include functional necessary services for the implementation of collaborative information system.

\section{APPLICATION OF OUR APPROACH CMCS}

The case concerns a company specialist on manufacturing, distribution and installation of products and solutions in industrial automation and electrical engineering.

Faced with the pressures of competition and growth issues importance, the company is looking more and more for improving its industrial performance in terms of cost, time, adaptability and traceability. Indeed, it wants its business processes to be more flexible in order to support strategic developments of the company; such as participation in scenarios with other business. The company recognized the need of a stronger coordination and collaboration. So, it wants to develop a platform that allows it to communicate with partners and to exchange information.

The objective is the establishment of a collaborative information system corresponding to the company's business processes and to the collaborative ones of inter-companies network. In this context, we apply our approach to provide a flexible architecture that meets this company needs.

\section{Phase 1: The study needs}

\section{Step 1: Development of business models of motivation}

The first step is to develop the business motivation model. Remember that the fundamental concepts of the model are: Ends (include the vision, goals and objectives) and means (include the mission, strategies and tactics).

The vision describes the company's look in the future without worrying about how to achieve it. The goal expresses a state in order to meet this vision. The objective is a measurable component that we can achieve with some time constraint to meet the goal. As for the mission, it represents the operational activities of the company that can achieve the vision. Finally, Strategies represent actions needed to achieve goals. BMM

By following these concepts, we develop an example of

\section{Step 2: Study of business organization}

The result of business organization leads us to develop a graphical representation of business processes.

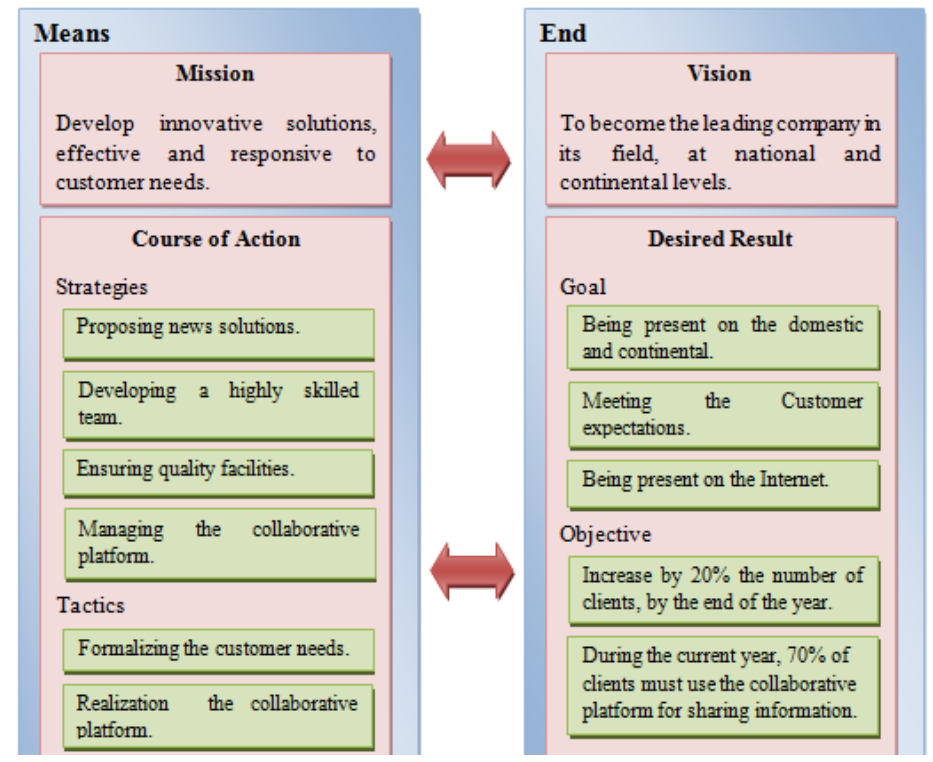

Figure 3. Example of BMM

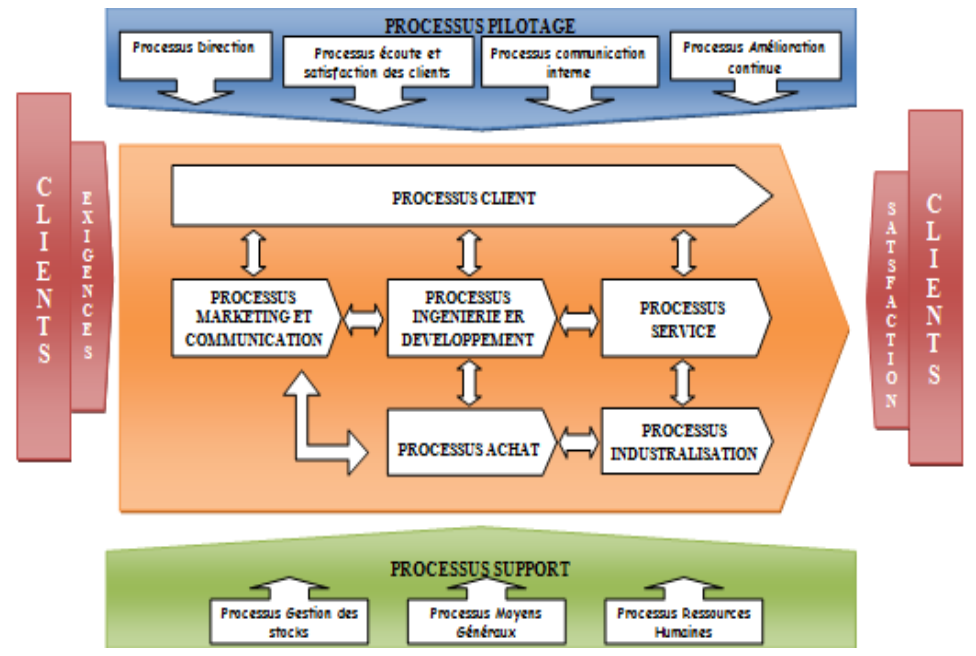

Figure 4. Process mapping

\section{Phase 2: Modelling and Design of the system}

Following our analysis, we focus on a specific process, we choose the purchasing one. Its main objective is to make goods or services available to internal users of the company with the best price, time and quality. Indeed, this process seeks to reduce the production costs, to ensure compliance of schedules and quality expected by customers.

Step 1: Business process modelling

We detail different activities of the purchasing process (see figure 5). The process begins with the definition of requirements formalized in a purchase request. This request generally specifies the following information:

- Description, type and characteristics of the product / service;

- The quantity to order;

- The delivery quality and desired time; 
- The budget for the purchase.

The expression of needs is considered as an event triggering the purchasing process. This can be done by the various departments of the company.

- Analysis of the purchasing needs

- Research suppliers and request for proposals

- Analysis of proposals and negotiation

- Establishment of the order

- Receipt of products and quality control

- Invoice Verification

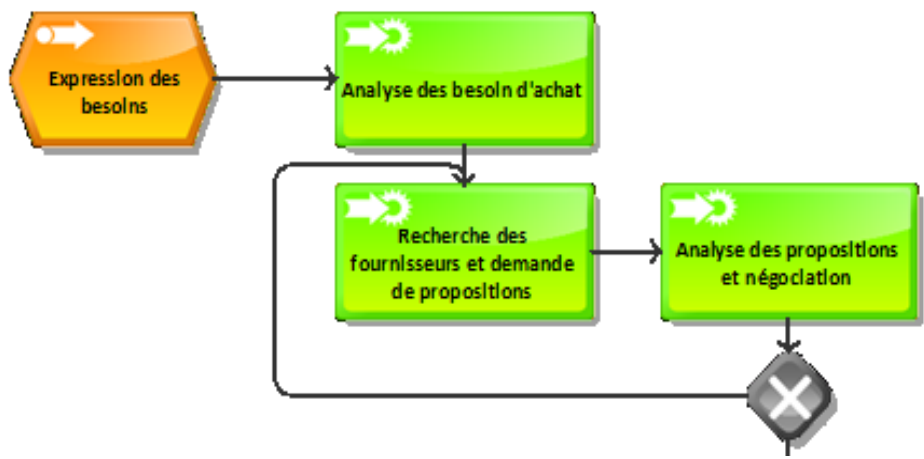

Figure 5. Part of the purchasing business process

Step 2: Modelling the collaborative business process

The purchasing collaborative process is modelled from the preceding description of business process. In this step, we describe the activities of partners involved in the collaborative process. In our case, collaborative alliances are already established between the producer (manufacturer) and partners of supply chain. The partnership created between the producer and supplier leads to the establishment of a framework-contract (legal support associated with partnership relations) between the two actors.

To study various acts of the purchasing collaborative process, we use the formalism BPMN (Business Process Modelling Notation). This notation will allow us to present the manual activities performed by actors of the chain (manufacturer and supplier of raw material) and automated activities supported by the collaborative platform.

In this context, we present two POOL partner (pool producer and pool supplier) and a POOL SIC. It contains two LANE (manufacturer module and supplier module). The figure below is an example of the purchasing collaborative process.

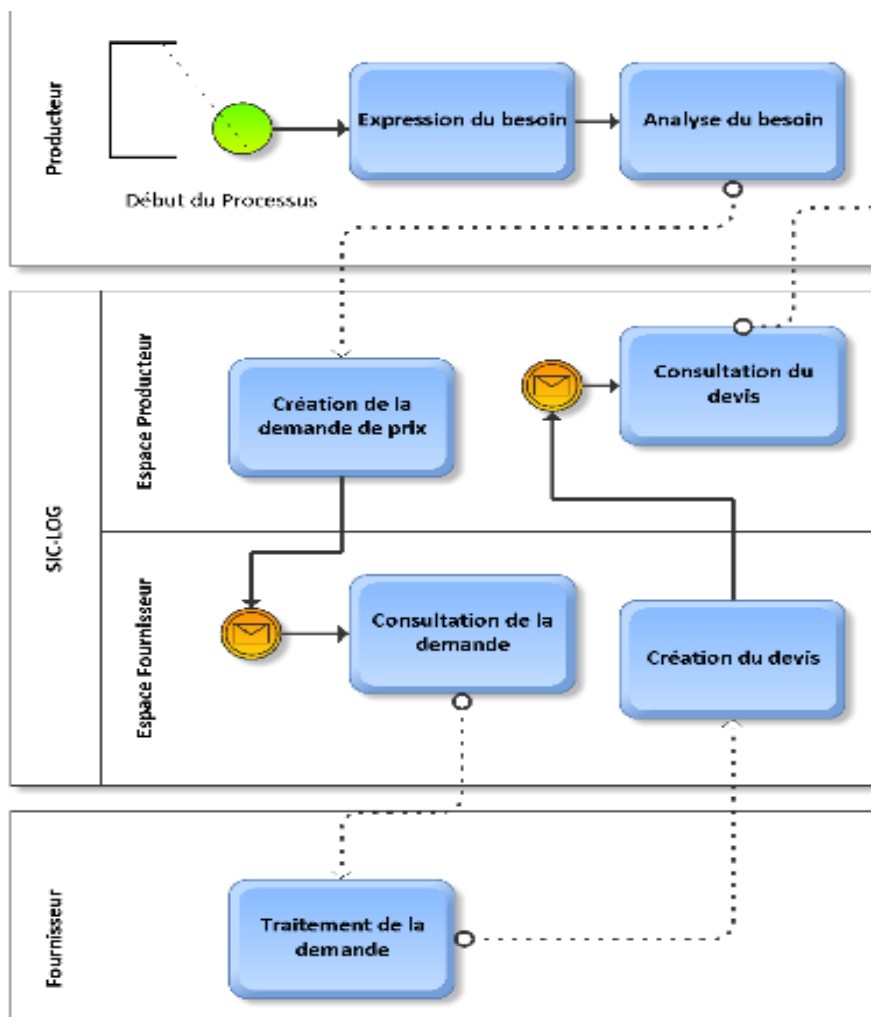

Figure 6. Part of collaborative process model

Step 3: Analysis and design of the system

- Diagram of use case

The use case diagram presented below shows few functionalities of managing the purchasing process.

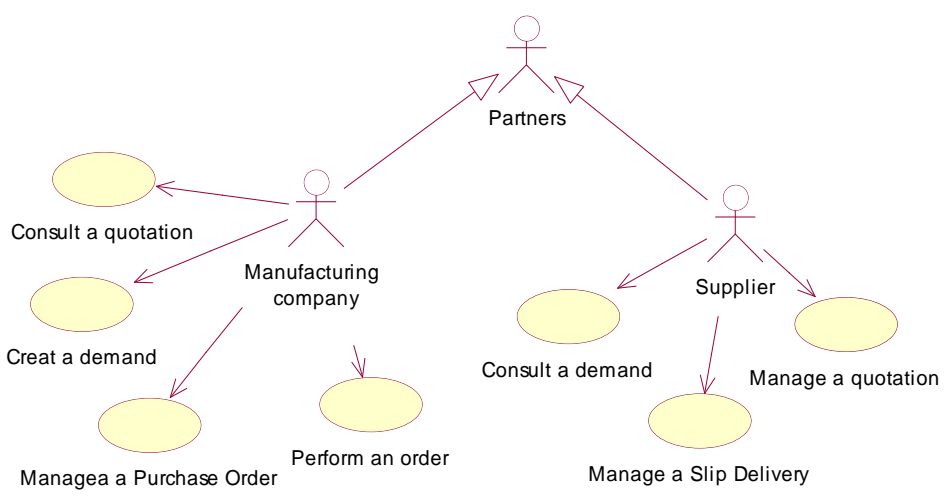

Figure 7. Use case diagram 
- Sequence diagram

The sequence diagram shows different interactions between actors of the purchasing process.

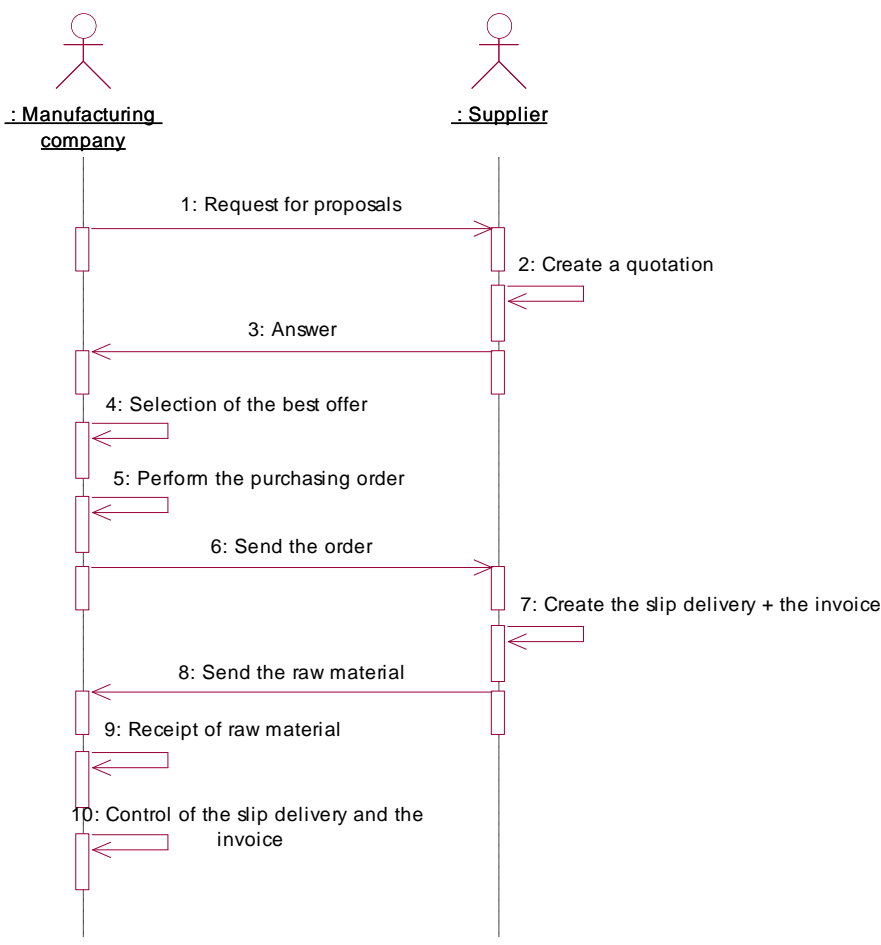

Figure 8. Sequence diagram

- Class diagram

The class diagram presented below expresses the static structure of the purchasing process.

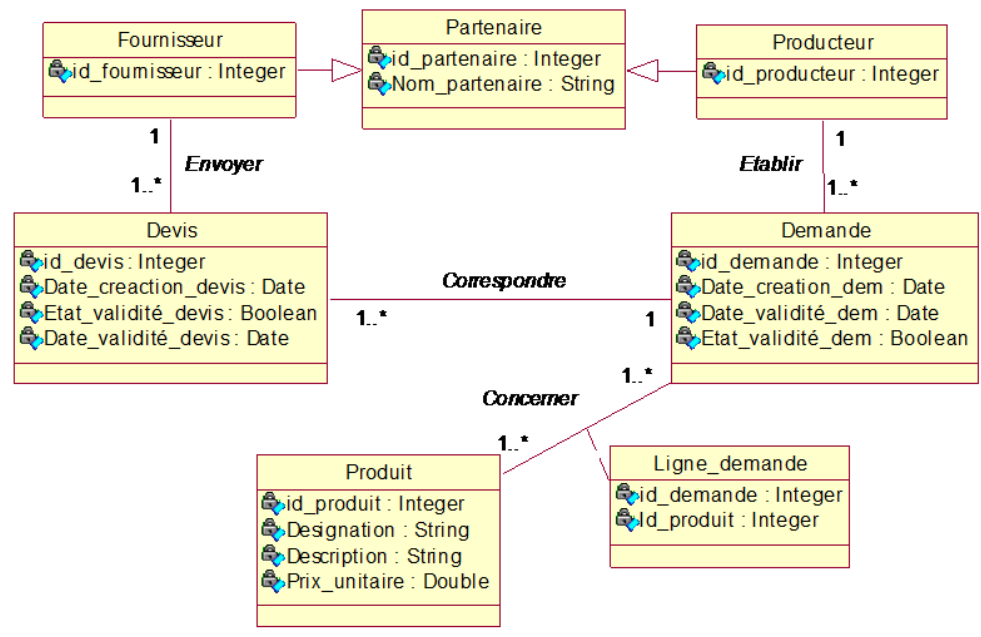

Figure 9. Class diagram

Step 4: Identification of functional services
We present in this step, functional blocks of our example. It represents functional services implemented in the system.

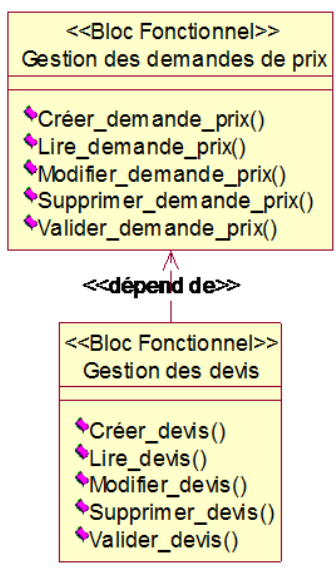

Figure 10. Functional Blocks

\section{CONCLUSION ET PERSPECTIVES}

In this paper we presented the methodological approach CMCS (Contextual Modelling of Collaborative System) for modelling and design of the collaborative information system dedicated to manage the supply chain. We used formalism BPMN and UML for modelling. As perspective, we are proposing the architecture of the system based on multi-agent systems and we are developing an example of system.

\section{ACKNOWLEDGMENT}

I would like to thank to my advisors Mr. B.AGHEZZAF and Mr. B.BENSASSI, for their invaluable guidance and many useful suggestions during my work on this paper. I would also like to express my gratitude to all those who gave me the possibility to complete this paper.

\section{REFERENCES}

[1] W. Dachry, B. Aghezzaf and B. Bensassi, "Integration of a collaborative information system in the global supply chain," the first International Congress: Computing and Engineering Sciences, ISI 2011, Meknes Errachidia, June 1 to 5, 2011

[2] H. Brandenburg, J-P. Wojtyna, "Process approach - Instructions for use," Eyrolles, 2006

[3] Sqli Consulting, "SOA book, guide the architect of the SI," 2nd edition Dunod, Paris, 2008

[4] K. Ben Driss, "SOA : pour une interopérabilité intrinsèque du Système d'Information," Tozeur, Tunisie, Novembre 2008

[5] R. Courdier, "Système d'Information Urbanisme des SI," http://personnel.univ-reunion.fr/courdier/cours/si/index.html, Date last accessed January 2012

[6] C. Devaux, "Urbanization and architecture service oriented (SOA)," http://www.aubay.com/. 2008

[7] K. Boukadi, "Coopération interenteprises à la demande : Une approche flexible à base de services adaptables," Thesis, November 2009

[8] Business Motivation Model, http://www.omg.org/spec/BMM/1.0/PDF, published in 2008

[9] A. Gautier, "Guide of implementation of the Systems Approach," 6th European Congress of Systems Science September 2005

[10] http://www.bpmn.org/

[11] Business Process Modeling Notation (BPMN), Version 1.0, May 2004. 
[12] P. Roques, "Uml in practice," Eyrolles, Mars 2008

[13] J. Simonin, “ Functional design of enterprise services," RSTI - ISI pages 37 to 61,2010

\section{AUTHORS PROFILE}

Wafaa Dachry was born in Casablanca in 1985. She received his professional master in logistics engineering, in 2008, from the faculty of science of Hassan II University, Casablanca, Morocco. In 2009, she joined the computer lab and decision support of the faculty of science, Hassan II University. Her actual main research interests concern collaborative information system for supply chain.

Brahim Aghezzaf is a professor in department of Mathematics and Computer, faculty of science, Hassan II University, Casablanca, Morocco. He is responsible of professional master in engineering and optimization of systems and logistics.
Her research focuses on multiobjective optimization, on metaheuristics, on operational researchand constraint programming...etc.

Bahloul Bensassi is a professor in department of physics, faculty of science, Hassan II University, Casablanca, Morocco. He is responsible of professional master in logistics engineering and professional master in Electronics, Electrical, Automation and Industrial Informatics. Her actual main research interests concern logistics, electronics, automation and industrial informatics...etc.

Adil Sayouti received his Degree in High Education Deepened in physical science in 1999 from Hassan II University, Casablanca, Morocco .In 2001 he obtained his diploma of superior studies in computer science and in 2003 a Microsoft Engineering Systems Certificate. In 2005 he joined the system architecture team of the ENSEM, Casablanca, Morocco. He received her Ph.D. from in 2009. His actual main research interests concern Remote Control over Internet Based on Multi agents Systems. 